$\begin{array}{ll} & \text { Etnográfica } \\ \text { etnográfica } & \text { Revista do Centro em Rede de Investigação em }\end{array}$

Antropologia

vol. 20 (2) | 2016

Vol. $20(2)$

\title{
Tempos e silêncios em narrativas: etnografia da solidão e do envelhecimento nas margens do dizível
}

Times and silences in narratives: ethnography of loneliness and aging in the limits of the speakable

\section{Raphael Bispo}

\section{(2) OpenEdition}

\section{Journals}

\section{Edição electrónica}

URL: https://journals.openedition.org/etnografica/4268

DOI: 10.4000/etnografica.4268

ISSN: 2182-2891

\section{Editora}

Centro em Rede de Investigação em Antropologia

\section{Edição impressa}

Data de publição: 1 junho 2016

Paginação: 251-274

ISSN: 0873-6561

\section{Refêrencia eletrónica}

Raphael Bispo, «Tempos e silêncios em narrativas: etnografia da solidão e do envelhecimento nas margens do dizível», Etnográfica [Online], vol. 20 (2) | 2016, posto online no dia 29 junho 2016, consultado o 10 fevereiro 2022. URL: http://journals.openedition.org/etnografica/4268 ; DOI: https:// doi.org/10.4000/etnografica.4268

\section{(c) (†) 8}

Etnográfica is licensed under a Creative Commons Attribution-NonCommercial 4.0 International License. 


\section{Tempos e silêncios em narrativas: etnografia da solidão \\ e do envelhecimento \\ nas margens do dizível}

\section{Raphael Bispo}

A proposta deste artigo é contribuir para uma etnografia do sentimento de solidão e abandono na velhice. Tal abordagem será efetuada a partir da análise da trajetória das chacretes, nome artístico de antigas dançarinas eróticas que durante as décadas de 1970 e 1980 foram famosas personagens da televisão brasileira. A solidão é entendida neste artigo como uma experiência emocional oriunda das negociações sociais cotidianas operadas pelos sujeitos acerca de suas próprias vidas. Tendo como base o caso de uma chacrete, é analisado ao longo do texto o trabalho da passagem do tempo na fabulação e na descrição de sentimentos considerados violentos e tortuosos por quem os vivencia. A experiência extrema de dor, sofrimento e solidão de uma mulher envelhecida liga-se a um trabalho de gestão de palavras e lembranças acerca de seu passado, demonstrando ser a solidão não um sentimento idiossincrático, "não relacional", mas, pelo contrário, resultado de contatos e trocas sociais.

PALAVRAS-CHAVE: emoções, solidão, histórias de vida, narrativas, velhice, gênero.

Times and silences in narratives: ethnography of loneliness and aging in the limits of the speakable - The purpose of this article is to contribute to an ethnography of loneliness and abandonment that may affect some people in certain moments of their lives. Such approach will be made here from the analysis of the trajectory of chacretes, erotic dancers who during the 1970s and 1980s were famous characters of Brazilian television. Loneliness is understood in this text as an emotional experience resulting from the daily negotiations operated by the subjects about their own lives. Based on the case of a single chacrete, the analysis focuses on the work of the passage of time in the fabling and description of feelings considered violent and tortuous by those who experience them. The extreme experience of pain, suffering and loneliness of an aging woman promotes the management of words and memories about her past, demonstrating that loneliness is not an idiosyncratic sentiment, "non-relational", but rather the result of contacts and social exchanges.

KEYWORDS: emotions, loneliness, life stories, narratives, ageing, gender.

BISPO, Raphael (raphaelbispo83@gmail.com) - Instituto de Ciências Humanas, Universidade Federal de Juiz de Fora; Centro de Estudos Sociais Aplicados, Instituto de Pesquisas do Rio de Janeiro, Brasil. 
INTRODUÇÃO

\begin{abstract}
"A compensação de a gente envelhecer, pensava Peter Walsh, retirando-se de Regent's Park, com o chapéu na mão, era simplesmente esta: que as paixões permanecem tão fortes como antes, mas adquire-se - afinal! - o poder que dá o supremo valor à existência: o poder de nos apoderarmos da experiência e volteá-la, lentamente, em plena luz" (Virginia Woolf, Mrs. Dalloway).
\end{abstract}

Em um influente trabalho, a antropóloga indiana Veena Das (2007) nos lembra que a pobreza de palavras e de linguagem em certos contextos relacionados à dor e ao sofrimento é associada por muitos a uma falta, a uma "selvageria", e não à dignidade e ao "humano". Essa não comunicação em muitos casos é vista também como algo idiossincrático, fruto de "traumas" pessoais e excepcionais, algo um tanto deslocado das realidades sociais. Sua perspectiva, porém, é justamente ir de encontro a esse comum diagnóstico ao tentar mostrar - a partir de suas incursões etnográficas junto às mulheres que vivenciaram o tortuoso processo de Partição da Índia em 1947 - que tal pobreza narrativa é resultado de uma dinâmica subjetiva que em muitos casos tende a tornar-se a grande virtude existencial desses sujeitos, aquilo que os permite refazer suas próprias vidas frente a dilemas provocados por suas vivências diárias junto a outras pessoas.

Remeto inicialmente neste artigo a tais reflexões de Das porque, durante minha pesquisa de campo junto a um segmento específico de mulheres que compuseram um importante setor do mercado do entretenimento e erótico durante os anos 70 no Brasil, o silêncio, o não narrar, a dificuldade em elaborar discursivamente o vivido era justamente uma de suas principais maneiras de expressar cotidianamente seus desconfortos sentimentais na atualidade, particularmente aqueles relacionados à solidão. Tais sensações de estarem sós no mundo, por vezes de grande dimensão e influência no cotidiano delas, sempre ocupavam as periferias do dizível e os cantos mais obscuros daquilo que é dignamente apresentável ao outro. As experiências de solidão não me pareciam assim algo idiossincrático, uma mera vontade pessoal, mas escondiam, na verdade, tramas e conflitos provocados pela convivência dessas mulheres com outras pessoas ao longo de suas existências.

Durante os anos de 2009 e 2011 estive de maneira constante ao lado de inúmeras chacretes pelos mais variados bairros da cidade do Rio de Janeiro a fim de realizar uma etnografia sobre suas trajetórias de vida. Chacrete é o nome artístico dado a antigas dançarinas eróticas, em sua maioria de camadas populares, que durante os anos 70 e 80 foram famosas personagens da televisão por bailarem no palco de Abelardo Barbosa, "o Chacrinha”, apresentador de TV. Seus programas reuniam um agitado auditório, brincadeiras e inúmeros cantores e artistas, sendo exibidos por cerca de 25 anos através de várias emissoras. Nessa cena artística popular, as chacretes eram personagens 
secundárias que se distribuíam pelo palco e tinham a função de dançar sensualmente para as câmeras. No entanto, a popularidade desses programas fez as chacretes serem muito conhecidas durante mais de 20 anos. Minha pesquisa de campo procurou se aproximar da geração mais antiga de dançarinas, aquela que foi considerada a pioneira, e que hoje possui um pouco mais de 60 anos de idade. A temática propriamente dita da solidão entre as chacretes pareceu-me importante um tempo depois de iniciada a pesquisa, conforme adentrava o mundo delas e adquiria maior intimidade. ${ }^{1}$

Diante disso, a proposta específica deste artigo é contribuir para uma etnografia das experiências de solidão e abandono de pessoas envelhecidas a partir das histórias de vida das chacretes. A ideia de solidão ganha neste artigo um contorno muito específico, fazendo necessariamente referência a um sentimento considerado por minhas interlocutoras como negativo, ruim e danoso às pessoas que o vivenciam. Nesse sentido, o texto procura construir um olhar mais apurado sobre o estado da solidão, entendida aqui não como algo estanque e de sentido único - uma mera "sensação de separação do outro" ou uma abstração despida das vivências concretas -, mas como uma experiência emocional oriunda das negociações cotidianas operadas pelos sujeitos acerca de suas próprias vidas. Foge-se com isso de uma visão essencialista e individualizada dessa emoção - a solidão como um sentimento da "não relação", da "falta de contatos" - para pensá-la como um sentimento múltiplo e repleto de contatos sociais, vivido de formas muito diferentes e que se atualiza justamente na diversidade das experiências sociais vividas pelos sujeitos.

$\mathrm{O}$ artigo está estruturado em cinco partes: na primeira, debateremos a importância do estudo das emoções nas ciências sociais, buscando compreender a pouca atenção dada a sentimentos "não relacionais", como é entendida a solidão; na segunda, destacamos a importância metodológica dos discursos no estudo da esfera emocional, levantando questões pertinentes ao uso de biografias no âmbito da antropologia; na terceira e quarta partes, a vivência do estar só será ilustrada por meio de um "caso" de minha pesquisa de campo, o de Marina Galvão, ${ }^{2}$ uma chacrete com 63 anos de idade; por fim, na última parte deste artigo, refletiremos o quanto a experiência de estar só na velhice não é provocada por uma carência inerente à condição de vida de certos segmentos da população idosa (eles estão sozinhos por falta de contatos decorrentes da velhice) mas, em muitos casos - e lembrando o que foi dito anteriormente recorrendo a Das (2007) -, a solidão associa-se ao trabalho de gestão de palavras e lembranças sobre o passado feito por muitos velhos desejosos por reconstruírem suas vidas diante de constantes desencontros sociais.

1 Para mais detalhes sobre a carreira de chacrete, ver Bispo (2012a, 2015, 2016).

2 Como de praxe, os nomes neste artigo são fictícios, apesar de todas as histórias aqui contadas serem autorizadas pelas chacretes. 


\section{POR UMA PERSPECTIVA ANTROPOLÓGICA DA SOLIDÃO}

Tornou-se quase banal, no âmbito das abordagens socioantropológicas dedicadas ao estudo das emoções, apontar para a negligência com que as esferas dos sentimentos foram tratadas pelos cientistas sociais desde o período de consolidação da sociologia e da antropologia enquanto campos de conhecimento legítimos, em meados do século XIX (Rosaldo 1980; Abu-Lughod 1990; Abu-Lughod e Lutz 1990; Coelho e Rezende 2010; Bispo 2012b). Mesmo com algum reconhecimento das afetividades como parte intrínseca da dinâmica da vida em sociedade, não foi ofertado a elas um espaço autônomo de reflexão neste período fundante. E, como demonstrei em outro lugar (Bispo 2012b), se outrora elas chegaram a ganhar aqui ou acolá algum maior relevo analítico - vide as próprias reflexões de Mauss sobre as regras de expressão obrigatória dos sentimentos nos rituais piaculares aborígenes (Mauss 2013 [1921]) ou mesmo a valorização malinowskiana da necessidade de o pesquisador de campo atentar para as "emoções estereotipadas" do espírito de seus nativos (Malinowski 1978) -, era necessariamente a partir de uma visão "social do emocional" que se conseguia fazer com que cientistas sociais olhassem uma vez ou outra para as sentimentalidades humanas.

Abriu-se flanco assim para uma série de pesquisas que analisavam sempre o "emocional" a partir de seu viés "relacional"/“social”, reconhecendo assim a capacidade da sociedade para regular em certa medida o campo dos afetos. Expressões sentimentais como o luto, o amor e a gratidão ganharam maior destaque analítico justamente por serem as afetividades que de maneira mais óbvia iluminam esse lado "social" de uma esfera sempre considerada como tendo um traço "individual" ou "privado" por excelência (Abu-Lughod 1986, 1990). Amor e admiração, nos lembram Coelho e Rezende (2010: 49), podem ser vistos como esforços emocionais de fusão com o outro, enquanto a amizade é reflexo do desejo de se estar próximo a certas pessoas. São, portanto, afetos eminentemente relacionais, abordam diretamente a interação. Todavia, sentimentos suscitados pela ausência do outro, que falam da percepção de uma falta de contatos - como a solidão e a saudade, por exemplo - parecem estar à parte desse traço relacional intrínseco e interativo existente na compreensão fusional do amor e da admiração bem como no caráter aproximativo reconhecido na amizade. Solidão e saudade seriam emoções que caminham para um lado oposto ao desses afetos, sendo não relacionais por princípio definidor.

Faço essa pequena digressão por acreditar que é justamente por isso que a solidão é um tema ainda hoje muito pouco abordado pelos cientistas sociais: se já não falamos muito das emoções ditas relacionais entre nós pesquisadores, mais dificilmente iríamos estudar aquelas que são consideradas uma expressão imediata da esfera do "indivíduo", do "fora de interações", da "ausência de outros", do "psicobiológico", logo, algo a ser tratado não por sociólogos 
e antropólogos, mas, sim, por psicólogos. A solidão muito pouco conseguiu romper os espaços disciplinares acadêmicos tão bem demarcados, mantendo-se no campo por excelência dos estudos da psicologia, esse "outro disciplinar" (Coelho e Rezende 2010: 47) que serve para excluir tudo aquilo que é considerado psicológico/individual do âmbito das ciências sociais.

Ora, certamente é por isso que os poucos estudos socioantropológicos dedicados à solidão na contemporaneidade desejam ressaltar o seu caráter "social" e pouco "individual" em suas principais premissas. Basicamente, a literatura dedicada ao tema produzida a partir dos anos 80 afirmou enfaticamente que o estar só é um sentimento decorrente da vida em sociedade e não fruto de idiossincrasias aleatórias dos sujeitos. Wood (1986) nos alertou para o facto de que a solidão é assim um sentimento paradoxal: experiência vista no senso comum como sendo "não social" mas que, no final das contas, seria por excelência um dos sentimentos mais sociáveis que existiria entre os seres humanos, considerando que ele aborda a separação, a dificuldade de compartilhamento com os outros (Wood 1986: 187). Em contraste com outros sentimentos, a solidão é eminentemente moral na perspectiva de Wood. Ilustra os "deveres" e "obrigações" de relacionamentos, as "expectativas" e "frustrações" dos indivíduos entre si.

As experimentações etnográficas de Pais (2006) em Portugal sobre a solidão caminham nesse sentido próximo de Wood ao pensar o "social" do solitário. Ele analisou pessoas sós em suas múltiplas manifestações a partir de inúmeros fragmentos de histórias de vida e cenários onde elas trafegariam, tal como nos asilos, nos internatos, pela Internet, entre moradores de ruas e pessoas idosas, entre outros nichos. Sua perspectiva analítica parte claramente da defesa do quanto há de "sociedade" no indivíduo solitário. Isso se torna muito mais claro quando deambulamos junto dele em suas incursões etnográficas, momentos estes em que busca antever os laços sociais presentes (ou ausentes) nos processos de desatadura que provocam a solidão. Com relação aos "sem-abrigo", por exemplo, a solidão seria decorrente de rupturas afetivas, falhas nas redes de apoio familiar em momentos críticos da vida. Isso levaria tais pessoas a morarem pelas ruas, muito mais até do que as desvinculações geradas no contexto do mundo do trabalho. Assim, teríamos aqui a chamada "dupla via da solidão" proposta pelo autor: indivíduos fogem da sociedade e, ao mesmo tempo, a sociedade foge dos indivíduos.

Logo, o que tais proposições de Wood e Pais atualizam nas teorias contemporâneas é aquilo que Simmel (1964) já desde o início do século XX considerava como sendo uma "contradição sociológica", ao analisar as consequências da presença ou ausência de certas pessoas ao compor um grupo: a ideia da existência de um indivíduo isolado no imaginário ocidental, que parece sempre reificar a solidão como um sentimento que só diz respeito à intimidade e ao afastamento dos outros. As análises de Simmel partem do pressuposto de que 
o isolamento (não necessariamente a solidão) é sempre definido na relação com a sociedade, isto é, o isolamento puro não existiria por completo porque para se considerar o "sozinho" é preciso pô-lo sempre em relação a um "social". Por isso a afirmação da existência de uma "contradição sociológica" no isolamento. O indivíduo estaria sempre em relação, seja de negação, inclusão, falta ou contraste com a sociedade. O indivíduo é, portanto, isolado apenas idealmente, porque há uma existência imaginada do social por este que se isola que é logo em seguida rejeitada, sem falar que esta outra parte da trama relacional (a "sociedade") continua ainda a vivenciar o laço pelo outro desfeito (Simmel 1964: 119).

\section{PONDERAÇÕES METODOLÓGICAS}

Faz-se importante também aprofundar a metodologia utilizada neste artigo para refletir sobre a solidão. Primeiramente, destaco que adoto como fundo analítico a proposta de Abu-Lughod e Lutz (1990) acerca do valor discursivo das emoções. Isso porque os sentimentos são compreendidos pelas autoras como elementos da linguagem social e, portanto, fundamentalmente formulados a partir de certas práticas e ideologias que regem uma determinada sociedade. Constantemente, Abu-Lughod e Lutz recorrem à noção de discurso de Foucault para elucidar essa perspectiva. O foco de preocupações não é o que é dito no discurso emotivo em si, mas, sim, o que é esse discurso, o que ele faz e como ele é formulado. A atenção está na prática do discurso emotivo e não no significado advindo de uma interpretação dele. Se a discursividade é constituída por falas que formam aquilo sobre o que se fala, nos dizem as autoras, ela não mantém com as emoções uma relação de referência, como se fosse algo externo aos sentimentos, mas, pelo contrário, compõe, dá vida e forma diretamente a dimensão subjetiva dos sujeitos. "Pode-se dizer que as emoções são criadas $n a$, e não modeladas pela fala no sentido de que são postuladas como uma entidade na linguagem, onde o seu sentido para o ator social também é elaborado" (Abu-Lughod e Lutz 1990: 12, grifos das autoras).

No entanto, seguir essa proposta de analisar a prática dos discursos solitários levou-me a tecer um percurso etnográfico direcionado à análise minuciosa das biografias das chacretes. Neste artigo e em outros trabalhos (Bispo 2014, 2016) tenho optado por uma etnografia person-centered, um olhar micro e aprofundado sobre poucas trajetórias. Tradicionalmente, os estudos sobre histórias de vida na antropologia são enfáticos em ressaltar o quanto a análise das biografias de nossos interlocutores nos permite reconstruir um processo sociocultural mais amplo por meio de experiências particulares (Mintz 1960; Debert 1986; Kofes 1994, 2001; Becker 1997). Assim, para pensar a solidão como um fenômeno social, parti não de abstrações generalistas que buscam concluir peremptoriamente o que é a solidão ou como ela é experimentada na velhice, 
mas, sim, de lembranças bastante pessoais de algumas chacretes. Se alguns relatos de vida podem parecer fragmentos desconexos, incoerentes e ambíguos à primeira vista, quando estes são considerados como "narrativas" surgidas no âmbito de uma interação etnográfica - nos termos de Kofes (1994: 121) -, eles obviamente sintetizarão as singularidades e interpretações de um sujeito, porém conseguirão ir além, promovendo uma referência mais objetiva capaz de transcender o sujeito e informar sobre o social. A narrativa de um único biografado não deixa de falar assim de sociedades e processos culturais mais amplos.

No entanto, por mais que Bourdieu (1996) já nos tenha desiludido quanto às biografias e ao seu caráter de todo coerente e orientado por sequências cronológicas ordenadas, este é ainda o melhor caminho para detalhar e recompor os variados rastros discursivos emocionais da vida das chacretes porque, principalmente, são elas próprias e suas narrativas dotadas de sequências e sentidos que incutem tal dimensão de deslocamento e coerência em suas próprias lembranças. As histórias de vida são sempre situações que as pessoas contam sobre elas mesmas, repletas com isso das mais variadas convenções de narração situadas em um contexto enunciativo. Um dos pontos altos das histórias de vida, diz-nos Becker (1997: 103), é justamente perceber as interpretações feitas pelos sujeitos do mundo no qual vivem e de seus períodos de transformação. Desconstruir a linearidade e coerência de uma vida não significa implodir ou menosprezar a maneira como os indivíduos compreendem e dão sentido ao transcorrer do tempo e de suas próprias trajetórias. Ora, nos diz Kofes (2001), esse suposto deslocamento objetivo e linear não pode prescindir das próprias experimentações que os indivíduos possuem do tempo passado, e aquilo que aparenta ser algo retilíneo e objetivo implica na verdade em "sentidos subjetivos naquele que se desloca, naqueles relacionados a este deslocamento e naqueles que já foram inscritos no próprio deslocamento" (Kofes 2001: 25).

Além disso, a literatura especializada sobre biografias também destaca que elas permitem construir um ponto de vista alternativo às documentações oficiais, principalmente por exporem "a versão que os oprimidos e desprivilegiados têm dos grandes e pequenos acontecimentos" (Debert 1986: 141). Ouvir as elaborações emocionais das chacretes era dar espaço a subjetividades que raramente ganham destaque nos canais oficiais da imprensa hegemônica. Seguindo aquilo que Corrêa (2003: 22) constatou ao estudar a biografia de antropólogas hoje um tanto desconhecidas para a maioria dos especialistas, o que começou a ficar claro na pesquisa era que o que rotineiramente é chamado de personagens secundários, supérfluos, de uma determinada cena artístico-cultural, teve tanta ou mais importância na sua construção e consolidação do que os ditos personagens principais. As biografias conseguem com isso subverter as memórias oficiais da televisão e trazer à tona as mais subterrâneas, aquelas que pouco ou quase nenhum espaço possuem para estarem em nosso dia a dia. Como bem disse Pollak (1989: 8), "distinguir entre conjunturas 
favoráveis ou desfavoráveis às memórias marginalizadas é de saída reconhecer a que ponto o presente colore o passado". É também, por essa mesma perspectiva, constatar que os longos silêncios sobre tais tempos, longe de conduzirem ao esquecimento generalizado geram, na verdade, as resistências que se impõem ao se fazer presentes perante o excesso de oficialidades.

Por fim, destaco que uma análise de um discurso emocional biográfico tal como a empreendida neste artigo auxilia-nos a questionar cânones da maneira como o conhecimento científico é tradicionalmente constituído, baseando-se em construções teóricas muitas das vezes generalistas e objetivas, afastadas das vivências de nossos interlocutores. A biografia permite reconhecer as implicações éticas e políticas da antropologia. Debert (1986: 144) nomeou este movimento de "contrageneralização", uma busca pelo refinamento dos grandes conceitos e modelos explicativos pelos quais as ciências sociais operam. Crapanzano (1980) segue por um caminho semelhante ao defender a proposta do uso das biografias justamente por elas permitirem que as consequências do "encontro etnográfico" tornem-se mais vívidas no texto, gerando uma atitude analítica que procura não encaixar o "nativo" em categorias externas, mas compreender os campos semânticos desses próprios agentes. ${ }^{3} \mathrm{~A}$ ideia do autor é que as histórias de vida podem vir a impedir a construção de uma narrativa estática acerca das pessoas que nos propomos estudar, dando um sentido à vida dos sujeitos que resulta, em muitos casos, de empreendimentos científicos um tanto autoritários e distanciados.

Nessa mesma obra, Crapanzano também nos fala que seu interlocutor biografado, Tuhami, poderia ser compreendido tal como um marroquino contemporâneo in extremis a partir do "encontro etnográfico" propiciado pela pesquisa. Tuhami, por meio da etnografia, tornou-se único e estereotipado ao mesmo tempo, e é desse mesmo modo à la Tuhami que solicito que o leitor observe a partir de agora a trajetória de vida de Marina Galvão. Poderíamos vê-la como uma chacrete in extremis, única e estereótipo a seu modo das dançarinas eróticas envelhecidas de Chacrinha. A figura do "nativo" convertido simplesmente em uma fonte de informações, destituído de nome e sem traços que o singularizem perde espaço aqui para uma rica e densa interlocutora. A partir dela pensaremos como a solidão frequenta as margens daquilo que é dizível e possui uma marca muito mais social do que idiossincrática.

3 A noção de "encontro etnográfico" de Crapanzano (1980) tornou-se bastante conhecida na cena antropológica americana e dita pós-moderna dos anos 80. “The ethnographic encounter, like any encounter between individuals or, for that matter, with oneself in moments of self-reflection, is always a complex negotiation in which the parties to the encounter acquiesce to a certain reality. This 'reality' belongs [...] to none of the parties to the encounter. It is - and this is most important - usually presumed to be the reality of one's counterpart to which one has acquiesced, to expedite the matter on hand" (Crapanzano 1980: ix). 


\section{A PESADA CORTINA DE SILÊNCIO OU “TÁ TUDO BEM!”}

Durante quatro ininterruptos anos Marina Galvão viveu internada em um hospital psiquiátrico da cidade do Rio de Janeiro, acusada de "velha maluca" pelo ex-marido, filhos e mãe. Não teve qualquer contato com a parentela ao longo de toda a sua penosa recuperação. Hoje, com a idade de 63, mora há mais de seis anos em uma residência financiada pela prefeitura voltada para a "ressocialização" de pacientes psiquiátricos cujas famílias não se dispuseram mais a recebê-los em casa, mesmo sendo considerados em "bom estado de saúde mental". A chacrete divide a residência com mais quatro pessoas vindas também de hospitais psiquiátricos e que possuem um perfil próximo do dela: são mulheres idosas, oriundas das classes populares e periféricas do Rio de Janeiro, de baixa escolaridade e sem qualquer renda, no máximo um salário-mínimo de auxílio da prefeitura.

Marina costumava reafirmar constantemente a mim e aos próximos a ocupação de chacrete que teve no passado e que todo mundo já não lembra mais. Ficou apenas dois anos nos programas de Chacrinha. Mas como é essa a atividade que exerceu mais reconhecida nos dias de hoje, apega-se a ela como um grande diferencial, mesmo que na época nunca tenha dado tanta importância assim a ela. Era mais um serviço como qualquer outro.

Marina está absolutamente só. Não possui nenhuma relação amorosa fixa há mais de dez anos. Não quer nem saber de homem ou sexo. Isso porque seu último marido, com quem ficou entre idas e vindas durante 20 anos, foi um dos que mais se mobilizou em prol de sua internação forçada. Não tem amigos há um tempo, nem gosta muito daquelas com quem compartilha a casa. Apenas as "suporta". Os poucos do passado nunca foram visitá-la no hospital. Perdeu o contato. Quanto à família (sua mãe ainda viva, sua irmã, seus filhos, netos e sobrinhos), bem... "Deixa pra lá, né? Tá tudo bem!" Marina não gostava de comentar sobre sua família durante um período da pesquisa de campo. "Tá tudo bem" era o discurso constante. Seco, direto e abolidor de qualquer diálogo. Seguindo Pais (2006: 163), poderíamos dizer que por vezes "as palavras são uma forma de calar enquanto que o silêncio é uma forma de falar”.

Isso se constatou de imediato no primeiro dia em que marcamos para que me narrasse a sua vida diante de um gravador. A conversa foi monopolizada por ela. Se antes era para ser uma entrevista - o que pressupõe perguntas e respostas a partir de um diálogo entre duas ou mais pessoas -, o encontro transformou-se em um monólogo de três horas em que Marina relatou exclusivamente sua vida artística para todos ouvirem. Não me deixava interromper a conversa. Geria ardorosamente toda a sua trajetória, impedindo mudanças de rumo para aqueles assuntos um tanto proibitivos. Quando tentava interferir, era logo interrompido. "Xi! Deixa eu falar! Isso eu falo depois"; "Deixa eu te contar isso aqui primeiro. Não interrompe!"; "Não, não! Isso não tem 
importância"; "Calma, calma, vou chegar lá. Agora a carreira é mais importante"; "Tá tudo bem com eles!"

Os silêncios de Marina dizem muito mais ou tanto quanto suas palavras. Sua tagarelice rotineira pode ser uma forma de ter em suas mãos o controle da situação da conversa, evitando assim inconvenientes. Mas é no encobrimento gerado pelo silêncio que certas questões mais se revelam aos outros ao seu redor quando comparado a qualquer narrativa oral esclarecedora. Aparente paradoxo: o silêncio, a princípio, é aquele que esconde, que não deixa ver, nada nos diz. Porém, em um ou outro caso, as grandes tramas da vida emergem justamente naquilo que não é dito. $\mathrm{O}$ silêncio fala, e muito. Ele gera mais entendimentos do que muitas perguntas e suas possíveis respostas escorregadias. Era através das narrativas silenciosas, portanto, que se expressavam os sentimentos solitários de Marina durante algum tempo de nossa convivência.

Ela pouco falava dos que dela afastaram-se e por quem ainda nutria algum sentimento. E isso não era só comigo. Suas companheiras de casa, os assistentes sociais, a própria equipe médica... Marina nunca foi de compartilhar com ninguém sobre temas dolorosos. Guardava tudo para si. Ou esquecia-os deliberadamente. A chacrete fez bastante uso de uma rede de proteção silenciosa tecida ao seu redor para evitar estar com os outros. Porque o silêncio é também uma forma de muitos indivíduos encontrarem um modus vivendi com aqueles que assistem de perto ao seu sofrimento (Pollak 1989: 5).

Expressão denunciadora da solidão, esta do "tá tudo bem". Balazs (1997: 683) afirma que ela capta os nadas que compóem a vida de muitos idosos esquecidos por seus parentes em clínicas de repouso, hospitais, etc. O problema maior que se revela por detrás do "tá tudo bem" é tão doloroso que ele nunca poderá ser dito plenamente, em sua integridade, nem sequer pensado. O silenciar é uma forma de gerir a dor, abafá-la, evitando que constrangimentos passados emerjam com toda a força de outrora. Por isso essa frase dotada de um espírito eufemístico, que busca suavizar o grande incômodo ao qual ela se refere. A cada vez que se aproxima de sua solidão, que lembra que está sozinha nesse mundo, Marina rapidamente encobre com "frases tranquilizadoras essa lucidez que a mataria" (Balazs 1997: 684). Esse tipo de gestão da memória baseada no ato de silenciar, afirma Pollak (1989: 5), não se refere propriamente a um esquecimento. Esse exercício memorial é toda a resistência que um indivíduo impotente possui em sua busca pela sobrevida. Nada se fala, pois se quer seguir adiante. O silêncio deliberado é, ainda para este autor (Pollak 1990), o indicador mais saliente do caráter duplamente limitado existente naquelas experiências de rupturas radicais e dramáticas pelas quais podem passar muitos indivíduos ao longo do curso de suas trajetórias, como os judeus em campos de concentração nazistas estudados por Pollak ou velhos "depositados" deliberadamente em abrigos por seus familiares. O limite do possível para a sobrevida sempre impõe limites ao dizível: o silêncio "pode 
falar, portanto, de forma credível sobre aqueles que sofreram, apesar de ser condição necessária para a superação do passado o esforço para esquecer ou mesmo não falar publicamente" (Pollak 1990: 12, tradução minha).

Além do mais, confessar os tormentos e assumir a solidão que eles provocam é um reconhecimento público do fracasso que se tornou uma vida. A solidão possui uma "natureza publicamente clandestina" ou "secretamente pública", nos termos de Sayad (1998: 112), que permite ser ela o tipo de sentimento que tem no silêncio uma de suas formas mais expressivas de narração. Assim, durante boa parte da pesquisa de campo, Marina não fazia nenhuma referência direta e espontânea às atrocidades sofridas ao longo da vida por conta de suas escolhas pessoais. As histórias sobre a vida familiar da chacrete parecem "slides congelados" (Das 1999: 33), ou mesmo "não narrativas" (Das 1999: 37), um conjunto de poucas memórias, em sua maioria positivas, utilizadas para narrar tais temáticas. Ela encobria a passagem do tempo por meio da seleção de determinados momentos. Esse controle sobre a própria narrativa revela um equilíbrio precário em torno de honras e vergonhas do passado. Era a "encenação" de narrativas em torno do "tá tudo bem" que tornava seus discursos reveladores da experiência de solidão - segundo Das, uma "pesada cortina de silêncio indicando uma presença oculta” (Das 2011: 11).

Tal "presença oculta" foi aos poucos sendo conhecida não só por mim, mas também por aqueles que conviviam com a chacrete. É importante dizer aqui, porém, que o ato de mentir e/ou silenciar pode garantir que algo "novo" surja em seu lugar certo tempo depois. Cho (2008) nos esclarece isso em sua análise sobre os traumas de prostitutas coreanas vivendo nos Estados Unidos. Mas esse "novo", aquilo que emerge após tempos longos de silêncios, não é necessariamente uma "verdade singular" (Cho 2008: 17). Como estamos no campo das margens, daquilo que não se pode saber com tanta certeza, o "novo" é apenas algo que faz sentido e transforma as perspectivas de vida daqueles que outrora se silenciavam. Não estou aqui, portanto, em busca dos segredos mais ocultos de Marina, daquilo que se esconde em seus discursos. Desejo apenas perceber como opera o trabalho do tempo em seus sentimentos de solidão, constatando o quanto de "sociedade" há nesse sentimento, atentando menos para o conteúdo explícito das narrativas e mais para a forma com tais histórias se entrelaçam à trajetória social da chacrete.

\section{DAQUILO QUE SE TORNA DIZÍVEL}

Após um longo período de vivência com a chacrete, tempo esse que se estendeu por quase dois anos de pesquisa de campo ao seu lado, percebia-a enredada em uma nova missão: retomar seus vínculos com a família. Sua aproximação vinha sendo feita de forma cautelosa, fosse para não constrangê-los em demasia, fosse porque ela mesma também queria se preservar. Vagarosamente, foi aos 
poucos conseguindo romper barreiras com relação à sua presença na família. "Eles estão me aceitando", costumava dizer em nossos encontros na casa de repouso. E esse movimento lhe permitia também falar mais sobre eles, deixando de lado um pouco os silêncios que rondavam esse tema-tabu durante boa parte do tempo em que convivemos. Essa nova possibilidade discursiva, fugir do silêncio, ligava-se portanto a sua vontade de recuperar e reabitar seu mundo devastado, não por uma suposta capacidade de transcendência, mas pelo exercício persistente e diário de retomar e refazer a própria vida.

A chacrete primeiramente conseguiu marcar encontros fortuitos com o filho mais novo, já que com ele conviveu boa parte da vida. Ele é "temporão", filho de seu último marido, e ela se afastou dele apenas por causa da internação. Havia mais de cinco anos que não se relacionavam daquela forma mais próxima como começaram a fazer a partir dali. Passaram a ir a cafés e restaurantes para bate-papos. A filha mais velha foi criada pela mãe de Marina desde pequena. Dela, a chacrete conseguiu aproximar-se também um tempo depois, mas sem grandes trocas de afeto. Pôde assim finalmente conhecer também a neta, que nasceu na época em que estava no hospital. Havia entre mãe e filha um ressentimento muito grande. A chacrete "deu para criar" a filha para a própria mãe, já que desejava correr o mundo apresentando-se como dançarina durante a década de 1970. Desde então, ambas sempre tiveram muitas dificuldades de estarem juntas, já que Marina passou a ser tida por boa parte dos entes como uma "abandonadora de lar". "Olha lá! Sua mãe rebolando a bunda na televisão! Ela deixou você aqui comigo para fazer essa pouca vergonha!" Foi assim que, segundo Marina, sua mãe desde cedo estimulou o distanciamento da filha de seu entorno. Ela sempre condenou suas escolhas, seus caminhos profissionais e, principalmente, seu estilo de vida. A chacrete costumava ser classificada como "ovelha negra da família" quando jovem. Marina era tida como um tanto "perdida" por escolher a arte como uma forma de sobrevivência e não ter tido um parceiro fixo durante muito tempo.

A chacrete vem desde então mantendo com seu núcleo familiar uma "intimidade à distância" (Pais 2006: 165), repleta de telefonemas que substituem abraços carinhosos e declarações de bem-querer recheadas de deficit de afetos e ressentimentos, conciliadas a atividades de atenção e cuidados de sua mãe doente. Marina não se sente mais um "estorvo", um "fardo" para a família, como dizia-me e constantemente apontam alguns trabalhos sobre velhice e instituições asilares (Balazs 1997; Pais 2006). Sua situação passeia mais pela experiência de ter sido considerada durante muito tempo persona non grata e, agora, claramente, enfrenta com desenvoltura uma espécie de "ajuste de contas". Ela sabe muito bem que a sua tão desejada proximidade afetiva familiar é instável, não duradoura, podendo ser descartada a qualquer momento. Mesmo assim, é com grande prazer que tenta reconquistar a todos. 
Marina vivenciava uma situação um tanto extraordinária e extrema de solidão que, nos termos de Elias (2001: 75), tem como marca uma pessoa em meio a muitas outras para as quais ela não tem qualquer significado, cuja existência não faz diferença. Durante parcela de sua vida, todos ao redor de Marina romperam qualquer laço de sentimento para com ela. Na declaração que segue, a chacrete conjuga confissões e queixas para iluminar os silêncios de outrora. Se antes nada falava sobre isso, descreve agora abertamente, como nunca antes para mim, sobre aqueles dos quais ela está mais próxima do que antes, mas que muito a magoaram no passado. Esse trecho de uma entrevista com a chacrete realizada em sua casa muito tempo depois de nos conhecermos descreve com tristeza e pesar o momento de sua internação forçada num hospital psiquiátrico, tornando mais claras as razões de tantos silêncios, palavras evasivas e subterfúgios.

"Eu estava carente, falei: 'Eu vou lá visitar meu filho e dar um dinheirinho para ele. Vou lá'. Era quase seis horas, interfono, meu filho bota a cara fora na janela no quarto andar. Eu sempre tenho a mania de tocar o interfone e olhar para cima, porque o pai dele sempre olhava, porque tinha oportunidade para me ver, né? Eu olhei para cima e vi meu filho, que eu tinha tocado o interfone. Demoraram para atender, eu toquei de novo. A madrasta dele atende, eu falei assim: 'É a Marina, mãe do Carlinhos, manda ele descer por favor'. 'Ele não está!' Eu ia falar: 'Eu vi ele'. Eu peguei e gritei: 'Carlinhos desce! É mamãe, eu quero falar com você! Não vou sair daqui se eu não falar com você'. Gritei mesmo. No quarto andar. Ele desceu! Demorou, mas desceu! Desceu com uma cara, emburrada, com raiva. Eu falei: 'O que houve, brigou com seu pai? Brigou com a... Por que hoje ela não quis me atender? Eu sempre venho te visitar, por que hoje ela cismou de dizer que você não está em casa?' 'Nada, nada, nada'. E não quis falar. Passou uns cinco minutos chega um carro de corpo de bombeiros. Um bombeiro saiu do lado direito, outro saiu do lado esquerdo, outro na frente e me imprensou no muro, no portão, com meu filho. 'A senhora vem com a gente!', 'Mas porque que eu vou com vocês?', 'Ah! uma mulher ligou para a gente dizendo que a senhora está fazendo escândalo aqui'. Eu falei: 'Não estou fazendo escândalo nenhum. Aconteceu isso, isso e isso. Isso não é motivo de chamar o bombeiro. Quem são vocês?' Aí eu olhei o carro para ver a placa. 'Nem placa vocês têm!' 'Nós somos o bicho. A senhora não vai vir por bem, vai vir por mal'. Aí eu falei: 'Porra, aí meu filho vai me dar como louca, escândalo, vão me agredir, vai ser pior'. Entrei calmamente e pegaram meu filho. 'Para que está levando o meu filho? Meu filho não fez nada!' 'Não, ele também vai'. Aí a minha preocupação! Não demos uma palavra e levaram para Engenho de Dentro para triagem no hospital. Disseram assim: 'Sua bolsa vai ficar com seu filho'. Me levaram para o outro lado 
da enfermaria e me deram uma injeção. Eu não vi meu filho mais. Me deu um sono danado. Eu comecei a procurar uma cama para eu dormir, para deitar. Quando eu achei uma cama vazia para eu deitar, um cara com uma voz de homem falou assim: 'Não deita não, senão vai ficar aqui para o resto da vida'. [...] Passou um mês, eu ligo para minha mãe, ligo para o pai do meu filho. Não! Passaram 45 dias! Eu falei para o médico: 'Eu sei que, por lei, você não pode me prender aqui por mais de 45 dias eu sendo uma pessoa sana. Aconteceu isso, isso e isso. Você não pode me manter aqui mais de 45 dias!' Ele falou: 'Tudo bem, por mim você já tem alta'. Assinou a alta. 'Agora tem que ter assinatura de alguém se responsabilizando por você ou você tem que ter um endereço para você ir'. Eu peguei e liguei para o pai do meu filho. Ele falou: 'Tá, vou te buscar'. Não foi. Eu me arrumei, ele não foi. Eu xinguei tanto ele no dia seguinte. Uma semana depois eu ligo para minha mãe. 'Mãe, deixa eu ficar aí! Eu pago à senhora. Por favor, eu quero sair!' 'Não, não dá, eu não quero'. 'Poxa mãe, a ambulância me leva. A senhora só assina o termo de responsabilidade. Eu vou pedir um empréstimo, eu vou pagar a locatária, e vou ficar lá naquela merda lá mesmo sem telha. Quando chover, vou para a rua, vou para algum lugar. Até eu conseguir outro lugar'. ‘Não, não. Não quero ter responsabilidade com ninguém'. Minha mãe é meio medrosa. Tudo bem, fiquei ficando no hospital, ficando, ficando. Aí que eu fiquei sabendo onde é que estava. Apanhei das loucas, puxão de cabelo, soco nas costas. Mas me defendia, não batia nelas, me defendia segurando. Aí fui ficando. [...] Eu não tinha mais nada o que fazer. 'O que vou fazer? Nada! Vou ficar aqui'. Depois de passar um tempo a gente teve um passe livre. Aquelas que tinham um bom comportamento. A gente não ficava lá dentro, a gente já saía. Ficava perto da cantina. A gente conversava. Comia salgadinho. [Você tinha contato com seus filhos nessa época?] Pera aí! Eu fiquei quatro anos e três meses sem contato com ninguém. Meu filho foi visitar uma vez só. Só meu filho, mais ninguém. Aí fui ficar na cantina. Fiquei com um problema de osteoporose, dor na coluna. Fiz fisioterapia e melhorei um pouquinho. O médico mandou que eu caminhasse todo dia, então no hospital tem uma ladeirinha assim que sobe. Então comecei a descer a ladeira e subir. Daí vi o Cristo. Eu falei: 'Daqui dá para ver o Cristo'. Fiz uma promessa. 'Me tira daqui, porque assim que sair daqui levo uma dúzia lindíssima de rosas brancas para o senhor. É só o que posso pagar nesse momento. Me tira daqui. Me tira daqui'. E foi, nunca perdi a esperança. Nunca! Aí, um dia chega... 'Ah! nós somos da ONG, nós temos uma casa da prefeitura! Então, nós queremos conversar com você, nós sabemos que você tem bom comportamento. Você e as outras que vi aqui fora'. Eu não aceitei. Me falaram de novo e eu não aceitei. Aí falaram assim: 'Marina, isso aí você vai para uma casa residencial, vai sair do hospital, Marina! Vai lá conversar’. Aí peguei e fui. Tô aqui hoje!” 


\section{NARRATIVAS, EMOÇÕES E MORALIDADES NA VELHICE}

Como demonstrei em outro artigo (Bispo 2014), a temática da solidão é algo constante e, ao mesmo tempo, quase ausente na literatura especializada dedicada ao envelhecimento. É um assunto que sempre tangencia reflexões sobre o envelhecer, sem necessariamente tornar-se um ponto de atenção especial. Tal paradoxo se instala por diversas razões. Uma delas é que, devido às representações sociais negativas sobre a velhice - fortemente associadas a estigmas ligados à decadência física e ao isolamento -, a solidão tornou-se um tema mais a ser confrontado do que pesquisado pelos especialistas. Valorizaram-se desde os anos 80 nas ciências sociais, por exemplo, trabalhos empíricos sobre a "vida ativa" dos idosos e suas redes de sociabilidade, principalmente de mulheres. ${ }^{4}$ Os bailes e universidades "da terceira idade", os clubes para aposentados e as conversas em praças, esquinas e bares entre "pessoas de idade" surgiram como lugares e momentos oportunos a fim de se acompanhar os idosos "em ação", principalmente nos estudos com marcas etnográficas.

Seguindo aquilo que Debert e Brigeiro (2012: 6) relatam ao buscarem situar historicamente os discursos contemporâneos críticos da gerontologia/geriatria acerca do "mito da velhice assexuada", o que está em jogo nesses trabalhos precursores é também um conjunto de discursos empenhados em rever estereótipos negativos da velhice, derrubando assim o que poderíamos chamar, parafraseando os autores, de "o mito da velhice solitária". A solidão tangencia uma ou outra passagem dessas pesquisas, sempre abordada de maneira um tanto superficial, emergindo como tópico a fim de se criticar o estereótipo do velho solitário. Peixoto (1997: 150), por exemplo, atentou em sua pesquisa para as "estratégias de fuga da solidão" por parte de idosos no Rio de Janeiro, com o intuito de mostrar aos leitores o quanto a inatividade da aposentadoria ou mesmo de situações de viuvez é, muitas das vezes, compensada por um dinamismo social e não por um afastamento da sociedade e sensações "terríveis" de solidão. ${ }^{5}$

Portanto, neste artigo, pretendeu-se também estimular uma reflexão sobre tal tema tão "ausente-presente" na literatura especializada, propondo pensar a solidão através de narrativas e moralidades, percebendo-a como algo bastante "social" e nem um pouco "idiossincrático". Certamente, ao abordar a solidão na velhice em minhas pesquisas sobre as chacretes (Bispo 2014, 2016), não busquei confirmar aquilo que estas pesquisas anteriores souberam muito bem desanuviar, o senso comum de que velhos são solitários e que sofrem por isso,

4 Essa constatação já podia ser verificada em Lins de Barros (1981, 1987). Motta (1998), Debert (1999), Peixoto (1997, 2000), Alves (2004) e Goldenberg (2008) percebem algo semelhante, mesmo partindo de experiências de campo com segmentos femininos da população bastante distintos.

5 Além deste trabalho, identifiquei reflexões mais detalhadas sobre a solidão na velhice nas pesquisas de Thompson, Itzin e Abenstern (1991), Elias (2001), Caradec (2004) e Pais (2006). 
mas, pelo contrário, busquei demonstrar a solidão como uma experiência emocional repleta de vicissitudes e ambiguidades, passível de ser vivida em qualquer etapa do ciclo da vida de uma pessoa e que a idade (seja ela qual for) é, sim, um marcador social da diferença que opera como fator importante para certas sensações particulares de solidão. Se Lutz (1988: 69) já nos disse que qualquer discurso sobre emoções é, pelo menos implicitamente, um discurso sobre gênero ("engendered emotion"), podemos afirmar que as emoções são também discursos sobre a idade, a classe social, a "raça"/etnia, a sexualidade, etc. No caso de Marina, por exemplo, é preciso considerar de imediato que sua experiência de solidão liga-se a outras variáveis sociais como o fato de ser uma mulher heterossexual, de ter tido sempre um comportamento considerado "inadequado" para o seu gênero, de ser de classe popular, não possuir uma renda fixa e ter a família como uma referência básica em sua vida, entre outras considerações que apontam que sua sensação de estar só liga-se a vários marcadores sociais da diferença que se entrelaçam na composição de suas subjetividades, não sendo ela, portanto, idiossincrática ou inerente à velhice.

Em outro lugar (Bispo 2016) apresentei um caleidoscópio variado de maneiras como as chacretes vivem a solidão. Isso porque, ao longo da pesquisa de campo, deparei-me com inúmeras e diferentes experiências de sentir-se só na velhice. As chacretes buscavam hierarquizar e classificar a solidão, o que só reforça a dimensão social desse sentimento. Os juízos de valores das chacretes se distribuíam e trafegavam entre qualificações positivas e negativas atribuídas ao estado de solidão, acompanhadas de uma diferenciação crucial que se estabelece entre dois modos de experimentá-lo: enquanto um ato de deliberação ou mesmo um estilo de vida que é buscado pela pessoa (a que chamei de "solidões deliberadas") ou enquanto uma solidão que acomete um sujeito ("solidões acontecidas").

O primeiro modo - as "solidões deliberadas" - assinala uma experiência que é predominantemente considerada produtiva e associada a uma escolha (Bispo 2016). Para uma parcela das chacretes, estar só nem sempre é algo ruim na velhice. A solidão pode ser um projeto de vida, algo considerado com uma escolha pessoal, portanto nem sempre é vinculada ao sofrimento. As máximas "antes só do que mal acompanhado" e "estar sozinho não é ser sozinho" parecem sintetizar de maneira informal tais argumentos. A vontade/escolha eram as palavras síntese de um projeto de vida em que estar só se tornava algo muito importante. Porém, a "solidão deliberada" não é sinônimo da incapacidade de algumas chacretes de estabelecerem vínculos afetivos com outras pessoas. O que procurei demonstrar é que a solidão na velhice para algumas delas podia vir a se caracterizar pela constituição de uma esfera privada distinta da vida familiar e/ou do trabalho, para as quais dedicaram grande parcela de seu tempo quando mais jovens. A família aparecia depois do envelhecimento delas como um ente que impedia sua valorização como indivíduo, no sentido de sujeito 
autônomo e decidido. A experiência de envelhecer, estar "solteira", "viúva", "sozinha" e/ou com os "filhos encaminhados" podia garantir assim uma relativa autonomia e independência às chacretes.

Todavia, neste artigo procurei desenvolver a partir de uma história de vida o segundo modo de avaliar a solidão entre as chacretes, a "solidão acontecida”. Ele corresponde geralmente à imagem da solidão mais convencional e compartilhada pelo senso comum, ou seja, como uma experiência geradora de sofrimento e mal-estar, a ser superada ou evitada a todo custo. Marina Galvão e algumas chacretes não avaliavam a solidão como um projeto "deliberado" de vida, contrariamente a outras amigas. As "solidões acontecidas" referiam-se geralmente a rupturas amorosas, a conflitos familiares, ao controle do marido, à ausência de amigos na "terceira idade", etc. Portanto, várias eram as "razões" e "causas" de um sentimento difuso, não desejado e bastante incômodo para certas chacretes. Nesse sentido, a experiência de campo junto a elas me permitiu compreender o "social" de um sentimento a princípio "não relacional" como a "solidão acontecida". Seus relatos sobre o estar só remetiam a todo instante a dinâmicas sociais e a trocas relacionais acontecidas ao longo de suas vidas, chamando a atenção para conflitos e crises da convivência social. Não havia, portanto, nada de idiossincrático ou inerente à condição de velha na sensação que muitas chacretes tinham de estarem sós no mundo. Elas não eram sozinhas simplesmente porque não tinham mais ninguém com quem compartilhar a vida, por terem atingido uma etapa do curso vital que aponta para uma escassez de trocas sociais. Por trás de suas solidões a princípio "individuais", o que existia, na verdade, eram trajetórias sociais repletas de dores, conflitos e esquecimentos gerados por suas vivências ao lado dos outros.

O caso de Marina Galvão ilustra com toda a força as "solidões acontecidas" das dançarinas e o caráter social do estar só. Pesquisas que articulam velhice às reflexões sobre instituições totais, como hospitais psiquiátricos e abrigos para idosos, são enfáticas em destacar que a condição de viver só se ressalta nestes locais devido às situações limites e precárias de muitos desses internatos, que não atendem às necessidades básicas de pessoas cada vez menos autônomas e de saúde frágil. ${ }^{6}$ Além disso, estar só se destaca por conta da separação do indivíduo do mundo exterior, de seus bens pessoais (a começar por sua morada) e por entrar em outro cenário com regras e ritmos próprios. ${ }^{7}$

6 Tais como os trabalhos realizados por Balazs (1997), Debert (1999), Elias (2001), Pais (2006) e Peixoto (2011).

7 Diz Pais (2006: 145): “Em visitas realizadas a alguns desses lares, na região suburbana de Lisboa, observei velhos frequentemente prostrados, distantes, numa indiferença sonolenta. Os entraves no acesso a alguns desses lares, onde a velhice parece ser um negócio lucrativo, deixam-nos adivinhar a miséria e maus-tratos que abundarão num ou noutro desses guetos consentidos". 
Mais do que isso, a condição asilar pode indicar também as dificuldades de relacionamento e cuidados que em casos como o de Marina levam familiares a defenderem a internação de seus velhos. Peixoto (2011) nos fala que a entrada de idosos nessas instituições não se dá sem traumas e raros são aqueles que para lá vão voluntariamente. A decisão está majoritariamente nas mãos da parentela, sendo "encoberta por não ditos que suscitam ressentimentos naquele que é asilado e certa culpabilidade naquele que interna o velho" (Peixoto 2011: 341). Tanto é que, nas narrativas da "solidão acontecida" de Marina, sua internação é fruto de uma "conspiração" orquestrada por pessoas próximas a ela, nunca o resultado de uma condição pessoal que a teria levado necessariamente ao hospital. Devido ao acúmulo de inúmeros conflitos ao longo da vida, Marina sentia-se então "aprisionada" por aqueles de que mais gostava. Sua solidão era resultado do ápice de uma trama de vinganças e ressentimentos. As negociações ou obrigações de se internar na velhice revelam tensões que geram nos idosos um sentimento de desconforto, ao perceberem que "a desejada proximidade afetiva é facilmente descartável" (Pais 2006: 164). O distanciamento de antigas redes de sociabilidade origina assim desvinculações sociais gradativas que não são rapidamente substituíveis nos novos espaços de vivência.

"Para aqueles que apostaram na reciprocidade e na solidariedade familiar, a ausência da família nessa etapa da vida [de idosos em instituições asilares] pode ser percebida como abandono, ela é muito mais sentida do que para aqueles que sempre viveram sós. Para esses, a institucionalização pesa somente quando perdem o contato com o mundo externo" (Peixoto 2011: 355).

É claro que não podemos generalizar a vida em asilos e hospitais como algo sempre penoso, espaço de maus-tratos, "depósito de velhos e doentes mentais”, um lugar por excelência da solidão. Lembro que Debert (1999: 107), por exemplo, estudou uma instituição para idosos cuja entrada era voluntária e representada pelos residentes como uma alternativa de independência e resgate de uma "multiplicidade de papéis sociais", de uma vida social que estaria em franco declínio fora dali. Destaco tais nuances negativas da condição asilar por conta da história de vida de Marina, o que corrobora a ideia de que a sensação de solidão nesses lugares liga-se às dinâmicas sociais e de poder experimentadas pelos internos antes de ali chegarem. No caso da chacrete, sua internação involuntária se deu por conta de possíveis "problemas mentais" numa fase avançada da vida. Mesmo em um contexto em que o projeto da Reforma Psiquiátrica Brasileira encontra-se consolidado, a internação involuntária é possível através de mecanismos judiciais, geralmente acionados por familiares mais próximos. Portanto, a solidão de Marina é também 
aflorada por uma "captura estatal" prevista na legislação vigente e respaldada por instâncias burocráticas. ${ }^{8}$

Enfatizado esse lado social das "solidões acontecidas" do mundo das chacretes, cabe aqui destacar que o trabalho de gestão de palavras e lembranças sobre a solidão feito por Marina tinha o intuito justamente de reconstrução de sua vida diante de inúmeros desencontros sociais. Marina buscava dignidade e humanidade na velhice ao silenciar a trama social de seu estado de abandono. Quando se estuda discursos emocionais como o de Marina, deve-se levar em consideração as modificações temporais na descrição de sentimentos passados. Das (2011: 34) nos lembra que a passagem do tempo nas histórias de vida está longe de ser algo que é meramente representado pelos sujeitos, ou seja, algo passado que apenas compõe suas consciências no presente. Isso significa dizer que o tempo é um agente que "trabalha" nas relações, permitindo que estas sejam reinterpretadas, reescritas e modificadas conforme os dilemas dos sujeitos que as vivenciam.

O fato é que Marina não se dedicou a me contar "seu passado" de imediato ou por inteiro, mas foi contando aqui e ali, quando surgia a ocasião, algo permitido pela experiência prolongada garantida pela pesquisa de campo. Isso não era uma questão de mera intimidade, mas de gestão do passado. Essa fragmentação dos dizeres só corrobora a ideia de que o esquecimento sobre eventos traumáticos, o silêncio em torno da solidão, não é aleatório mas, sim, parte importante do que é dito, responde a demandas sociais. O dizer não se opõe ao esquecer, eles são extensões um do outro. Ao esquecer está se dizendo algo também. Portanto, essa passagem do ato de silenciar para a palavra em profusão sobre o estado de solidão de Marina apresentada ao longo do texto não é idiossincrática. Ela segue os movimentos da vida da chacrete e suas formas de gerir os sofrimentos do cotidiano perante o contato com os outros. Pollak (1989: 9) já nos alertou que certas lembranças traumatizantes geralmente esperam o momento propício para serem narradas pela pessoa que as sofre. Isso porque esse sofrimento liga-se a inúmeras dinâmicas sociais e não a meros caprichos dos indivíduos.

Marina poderia ter rompido de vez os laços com seus familiares de origem. Suas relações poderiam ter sido apagadas de sua vida porque eram fonte de memórias dolorosas. Embora nunca falasse sobre isso, sua intenção foi a de reaver esses laços, recompor as fissuras, sair da solidão. Marina sempre buscou uma reaproximação com a parentela. Assim, parecia ter chegado o momento de

8 Para mais detalhes sobre a Reforma Psiquiátrica Brasileira, ver Amarante (1996). Vale notar que “internação involuntária” não é sinônimo de “internação compulsória”. Basicamente, a primeira necessita de uma autorização familiar e judicial. A segunda não requer qualquer aval da família e da justiça e vem sendo polemicamente reativada pelo Estado na atualidade em contexto da chamada "epidemia do crack". 
a chacrete revisar a trajetória afetiva quando decidiu tentar aproximar-se dos parentes. O contato amistoso com a família fazia com que o fantasma que esse grupo se constituiu em seu passado recente no asilo pudesse a partir de então começar a ser exorcizado. Seu depoimento trata de uma gama variada de ressentimentos acumulados no tempo que jamais puderam se exprimir publicamente, mas que, agora, urgiam vir à tona. Sua solidão, portanto, descreve pelo silêncio uma vida repleta de relações fraturadas e não uma condição inevitável da velhice, resultado da "falta de contatos".

Em seus trabalhos, Das (1999) aponta que o caráter não narrativo de certas experiências está ligado à sua inclusão ou não na "cultura", isto é, naquilo que a pessoa compreende como sendo o humano, o possível de existir enquanto forma de vida. O não dizível liga-se a uma compreensão de desumanidade do acontecido, do quanto aquilo não é "cultural", "normal”. Inspirada nos escritos de Wittgenstein, a autora distingue as "formas de vida verticais" - narrativas que promovem uma hierarquização do que é ou não humano ("é máquina", "é coisa") - das "formas de vida horizontais", aquelas que se caracterizam pela variação do que é o humano, logo, falam de experiências em que não existe a fronteira do que é ou não pertencente à humanidade, mas, sim, o tipo e variação interna daquilo que é considerado humano. Nas palavras de Das, o indizível é composto "por formas de vida que não são vistas como pertencentes à própria vida" porque "levantam certas dúvidas quanto à própria vida, e não apenas quanto às formas que ela pode assumir" (Das 1999: 39). O indizível margeia as "formas de vida verticais", não as "horizontais".

"As violações do corpo não podem ser ditas, porque pertencem ao mundo das coisas, ou das feras, ou das máquinas, contrastam com as violações que podem ser inscritas na vida cotidiana, quando se pode permitir que o tempo realize seu trabalho de reinscrição, reescritura ou revisão das memórias da violência" (Das 1999: 39).

Existe no que é indizível uma "energia moral" na recusa de representar algumas violações subjetivas. Mas é importante aqui sublinhar que isso não significa dizer que a dor oriunda de experiências drásticas de solidão é intrinsecamente incomunicável. Palavras faltam quando o limite do humano é testado. As narrativas passam a ser possíveis quando um trabalho de gestão consegue tornar humanizável aquilo que outrora era visto como contrário à natureza, passando para a linguagem corrente aquilo que pertencia à ausência de linguagem.

O que Marina foi capaz de fazer foi justamente dar voz e mostrar os prejuízos causados a ela através de complexas transações entre corpo e linguagem, favorecendo uma domesticação e consequente renarração de fatos impactantes e vistos como desumanos. Minha etnografia ao lado de Marina me mostrou 
um delicado trabalho de autocriação por parte da chacrete. Fazer uma pesquisa de campo sobre sua vida era acompanhar a densa e demorada tessitura de uma aproximação com a família, só percebida um tempo depois do trabalho de campo. Aquilo que outrora estava cercado por uma cortina de silêncios ganhava uma nova configuração por conta dessa capacidade da chacrete de ressignificar por meio do tempo suas dores, trazendo tudo para a órbita do humano. O tempo é imprescindível para a humanização da dor, pensa Das (2011), ele realiza um trabalho dentro dos contornos da vida: ele domestica e socializa aquilo que outrora não era nem narrável. Logo, o tempo também possui uma agência, trabalha. Das indica a partir de suas interlocutoras indianas que saber lidar com o tempo significa atuar diretamente na reconstrução de relações para, com isso, voltar a habitar o mundo. O trabalho do tempo colocou Marina como sujeito produtor de sua solidão, atuante no processo de reconstrução de suas próprias relações familiares.

No entanto, apesar de todo o trabalho, Marina sabe que ainda não é querida por ninguém como deseja. Sabe que há um bom tempo deixou de ter sentido para os outros, que sua vida não gera preocupação alguma. Nem mesmo sua carreira artística tem algo de valoroso para ser contado. Sua passagem pelo show de Chacrinha é tida por todos especialistas como "irrelevante". Se morrer, já constatou que ninguém estará ao lado dela, até mesmo aqueles que, a princípio, deveriam gostar de tê-la ao redor, tal como os seus familiares, com quem vem mantendo agora uma "intimidade à distância". O argumento de Elias (2001) em torno da solidão dos moribundos concentra-se justamente no afastamento sentimental dos vivos devido ao incômodo que o moribundo pode provocar. Fala de seus últimos dias, nos estágios finais da vida, quando estar observando a morte torna-se um grande problema para os sujeitos de boa saúde. "A fragilidade dessas pessoas é muitas vezes suficiente para separar os que envelhecem dos vivos. Sua decadência as isola", diz Elias (2001: 8). Só que, por meio dos dados que expusemos neste artigo, podemos pensar que esses afastamentos começam muito antes e de forma menos nítida do que na eminência da morte em uma cama de hospital. Marina há tempos vem sendo deixada de lado por todos. Sua solidão é, portanto, eminentemente social. 


\section{BIBLIOGRAFIA}

ABU-LUGHOD, Lila, 1986, Veiled Sentiments: Honor and Poetry in a Bedouin Society. Berkeley e Los Angeles, University of California Press.

ABU-LUGHOD, Lila, 1990, "Shifting politics in Bedouin love poetry", em C. Lutz e L. Abu-Lughod (orgs.), Language and the Politics of Emotion. Cambridge, Cambidge University Press, 24-45.

ABU-LUGHOD, Lila, 2000, “Locating ethnography”, Ethnography, 1 (2): 261-267.

ABU-LUGHOD, Lila, e Catherine LUTZ, 1990, "Introduction: emotion, discourse and the politics of everyday life", em C. Lutz e L. Abu-Lughod (orgs.), Language and the Politics of Emotion. Cambridge, Cambidge University Press, 1-23.

ALVES, Andréa Moraes, 2004, A Dama e o Cavalheiro: Um Estudo Antropológico sobre Envelhecimento, Gênero e Sociabilidade. Rio de Janeiro, Editora FGV (Fundação Getulio Vargas).

Amarante, Paulo, 1996, O Homem e a Serpente: Outras Histórias para a Loucura e a Psiquiatria. Rio de Janeiro: Fiocruz.

BALAZS, Gabrielle, 1997, "A solidão", em Pierre Bourdieu (org.), A Miséria do Mundo. Petrópolis, Vozes, 683-691.

BARROS, Myriam Lins de, 1981, “Testemunho de vida: um estudo antropológico de mulheres na velhice", em Maria Laura Cavalcanti, Maria Luiza Heilborn e Bruna Franchetto (orgs.), Perspectivas Antropológicas da Mulher 2. Rio de Janeiro, Jorge Zahar, 11-70.

BARros, Myriam Lins de, 1987, Autoridade e Afeto: Avós, Filhos e Netos na Família Brasileira. Rio de Janeiro, Jorge Zahar.

BECKER, Howard, 1997, "A história de vida e o mosaico científico”, em H. Becker, Métodos de Pesquisa em Ciências Sociais. São Paulo, Hucitec, 101-115.

BISPO, Raphael, 2012a, "Gênero e carreiras artísticas na emergente indústria cultural brasileira”, Comunicação e Sociedade, 21: 79-94.

BISPO, Raphael, 2012 b, Jovens Werthers: Amores e Sensibilidades no Mundo Emo. Rio de Janeiro, Multifoco.

BISPO, Raphael, 2014, "Retratos da solidão: sofrimento e moralidades femininas na velhice", Sociedade e Cultura, 17 (1): 41-50.

BISPO, Raphael, 2015, "Vivendo do rebolado: feminilidades, corpos e erotismos no show business televisivo", Mana, 21 (2): 237-266.

BISPO, Raphael, 2016, Rainhas do Rebolado: Carreiras Artísticas e Sensibilidades Femininas no Mundo Televisivo. Rio de Janeiro, Mauad X/Faperj.

BOURDIEU, Pierre, 1996, “Apêndice 1: a ilusão biográfica”, em P. Bourdieu, Razões Práticas: Sobre a Teoria da Ação. Campinas, Papirus, 74-82.

CARADEC, Vincent, 2004, Vieillir après la retraite. Paris, Presses Universitaires de France.

CHO, Grace M, 2008, Haunting the Korean Diaspora: Shame, Secrecy and the Forgotten War. Minneapolis, University of Minnesota Press.

COElho, Maria Claudia, e Claudia Barcellos REZENDE, 2010, Antropologia das Emoções. Rio de Janeiro, Editora FGV (Fundação Getulio Vargas).

CORRÊA, Mariza, 2003, Antropólogas e Antropologia. Belo Horizonte, UFMG.

CRAPANZANO, Vicent, 1980, Tuhami: Portrait of a Moroccan. Chicago e Londres, The University of Chicago Press.

DAS, Veena, 1999, "Fronteiras, violência e o trabalho de campo: alguns temas wittgensteinianos", Revista Brasileira de Ciências Sociais, 14 (40): 31-42. 
DAS, Veena, 2007, Life and Words: Violence and the Descent into the Ordinary. Berkeley, University of California Press.

DAS, Veena, 2011 , "O ato de testemunhar: violência, gênero e subjetividade", Cadernos Pagu, 37: 9-41.

DEBERT, Guita, 1986, "Problemas relativos à utilização da história de vida e história oral”, em Ruth Cardoso (org.), A Aventura Antropológica: Teoria e Pesquisa. São Paulo, Paz e Terra, 141-156.

DEBERT, Guita, 1999, A Reinvenção da Velhice. São Paulo, Edusp.

DEBERT, Guita, e Mauro BRIGEIRO, 2012, "A erotização da velhice", em Anais do $36 .^{\circ}$ Encontro Anual da Anpocs, Águas de Lindóia, SP, 21-25 de outubro de 2012, disponível em $<$ http://www.anpocs.org/portal/index.php?option $=$ com_docman\&task=doc_view\&gi$\mathrm{d}=8225$ \&Itemid $=76>$ (última consulta em maio de 2016).

ELIAS, Norbert, 2001, A Solidão dos Moribundos. Rio de Janeiro, Jorge Zahar.

GOldenberG, Miriam, 2008, Coroas: Corpo, Envelhecimento, Casamento e Infidelidade. Rio de Janeiro e São Paulo, Record.

KOFES, Suely, 1994, "Experiências sociais, interpretações individuais", Cadernos Pagu, 3 : 117-141.

KOFES, Suely, 2001, Uma Trajetória, em Narrativas. Campinas, Mercado das Letras.

LUTZ, Catherine, 1988, Unnatural Emotions: Every Day Sentiments on a Micronesian Atoll and Their Challenge to Western Theory. Chicago, The University of Chicago Press.

MALINOWSKI, Bronislaw, 1978, Argonautas do Pacífico Ocidental. São Paulo, Abril Cultural.

MAUSS, Marcel, 2013 [1921], "A expressão obrigatória dos sentimentos (rituais orais funerários australianos)", em Marcel Mauss, Ensaios de Sociologia. São Paulo, Perspectiva, 325-335.

MINTZ, Sidney, 1960, Worker in the Cane: A Puerto Rican Life History. New Haven e Londres, Yale University Press.

MOTTA, Flávia de Mattos, 1998, Velha é a Vovozinha: Identidade Feminina na Velhice. Santa Cruz do Sul, Edunisc.

PAIS, José Machado, 2006, Nos Rastos da Solidão: Deambulações Sociológicas. Porto, Âmbar.

PEIXOTO, Clarice, 1997, "Histórias de mais de 60 anos", Estudos Feministas, 5 (1): 148$-158$.

PEIXOTO, Clarice, 2000, Imagem e Envelhecimento: As Fronteiras entre Paris e Rio de Janeiro. São Paulo, Annablumme.

PEIXOTO, Clarice, 2011, "Sobre a institucionalização da velhice e as condições de asilamento”, em Mirian Goldenberg (org.), Corpo, Envelhecimento e Felicidade. Rio de Janeiro, Civilização Brasileira, 341-356.

POLLAK, Michael, 1989, "Memória, esquecimento, silêncio", Estudos Históricos, 2 (3): 3-15.

POLLAK, Michael, 1990, L'expérience concentrationnaire: Essai sur le maintien de l'identité sociale. Paris, Editions Métailié.

ROSALDO, Michelle, 1980, “Toward an anthropology of self and feeling”, em R.A. Shweder e R.A. Le Vine (orgs.), Culture Theory: Essays on Self, Mind and Emotions. Cambridge e Londres, Cambridge University Press, 137-157.

SAYAD, Abdelmalek, 1998, A Imigração ou os Paradoxos da Alteridade. São Paulo, Edusp.

SIMMEL, Georg, 1964, "The isolated individual and the dyad", em Kurt H. Wolff (org.), The Sociology of Georg Simmel. Nova Iorque, The Free Press, 1 18-144. 
ThOmpson, Paul, Catherine ITZIN, e Michele ABEnstern, 1991, I Don't Feel Old: The Experience of Later Life. Oxford, Oxford University Press.

WOOD, Linda, 1986, "Loneliness", em R. Harré (org.), The Social Construction of Emotions. Oxford, Basil Blackwell, 184-208. 